\title{
Research Article \\ Study on Synthesis and Photocatalytic Activity of Porous Titania Nanotubes
}

\author{
Huang Liu, Yanhua Zhang, Hongtao Yang, Wei Xiao, and Lanlan Sun \\ Research Institute for New Materials Technology, Chongqing Key Laboratory of Environmental Materials \& Remediation Technologies, \\ Chongqing University of Arts and Science, Chongqing 402160, China
}

Correspondence should be addressed to Yanhua Zhang; zyhcoco@163.com and Wei Xiao; showame@aliyun.com

Received 23 January 2016; Revised 30 May 2016; Accepted 31 May 2016

Academic Editor: Angela De Bonis

Copyright (C) 2016 Huang Liu et al. This is an open access article distributed under the Creative Commons Attribution License, which permits unrestricted use, distribution, and reproduction in any medium, provided the original work is properly cited.

\begin{abstract}
Using the common natural cellulose substance (filter paper) and triblock copolymer (Pluronic P123) micelles as dual templates, porous titania nanotubes with enhanced photocatalytic activity have been successfully synthesized through sol-gel methods. Firstly, P123 micelles were adsorbed onto the surfaces of cellulose nanofibers of filter paper, followed by hydrolysis and condensation of tetrabutyl titanate around these micelles to form titania layer. After calcination to remove the organic templates, hierarchical titania nanotubes with pores in the walls were obtained. The sample was characterized by X-ray diffraction pattern (XRD), scanning electron microscopy (SEM), transmission electron microscopy (TEM), nitrogen adsorption/desorption, Fourier Transform Infrared Spectroscopy (FT-IR), Ultraviolet-Visible Diffuse Reflectance Spectroscopy (UV-Vis DRS), and X-ray photoelectron spectroscopy (XPS). As compared with commercial P25 catalyst, the porous titania nanotubes prepared by this method displayed significantly enhanced photocatalytic activity for degrading methyl orange under UV irradiation. Within 10 minutes, the porous titania nanotubes are able to degrade over $70 \%$ of the original $\mathrm{MO}$, while the value for the commercial Degussa P25 is only about $33 \%$.
\end{abstract}

\section{Introduction}

As the most promising photocatalyst, titania materials $\left(\mathrm{TiO}_{2}\right)$ have been expected to play an important role in a wide range of fields including environmental pollution control, photocatalyst, and high effect solar cell due to their excellent physicochemical properties such as relatively high photocatalytic activity, thermal and chemical stability, nonphoto corrosive, being nontoxic, being capable of photooxidative destruction of most organic pollutants, and low cost [1-5]. Numerous recent research has shown that the photocatalytic activity of titania materials is mainly influenced by the surface area, grain size, crystallinity, crystal structure, band gap, and so forth [6-9]. Normally, the anatase-type titania materials (band gap energy $3.2 \mathrm{eV}$ ) generally exhibit much higher photocatalytic activity than that of rutile (band gap energy $3.0 \mathrm{eV}$ ) [10-13]. Therefore, preparation of anatase phase of titania nanomaterials has attracted increasing attention and many methods have been developed, such as anodization of titanium foil $[14,15]$, the hydrothermal treatment of $\mathrm{TiO}_{2}$ nanoparticles with alkali solution $[16,17]$, surfactant-assisted templating methods $[18,19]$, hydrolysis of TiF4 under acidic conditions $[20,21]$, and deposition of sol-gels within templates [22].

In this paper, we synthesized titania nanotubes through sol-gel method with employed natural cellulose substance (filter paper) as template. The resulting titania nanotubes truly inherit the complex network structures and hierarchical morphologies of the initial cellulose substance and exhibit obviously enhanced photocatalytic activity compared with commercial P25.

\section{Experimental}

2.1. Reagents. Commercial ashless quantitative filter paper (GB/T1914-93) was used throughout the work. Triblock copolymer Pluronic P123 (PEG-PPG-PEG) and titanium $n$-butoxide $\left[\mathrm{Ti}\left(\mathrm{O}_{n} \mathrm{Bu}\right)_{4}, \mathrm{TBT}, 99 \%\right]$ were purchased from Aldrich. All aqueous solutions were prepared using Milli-Q 


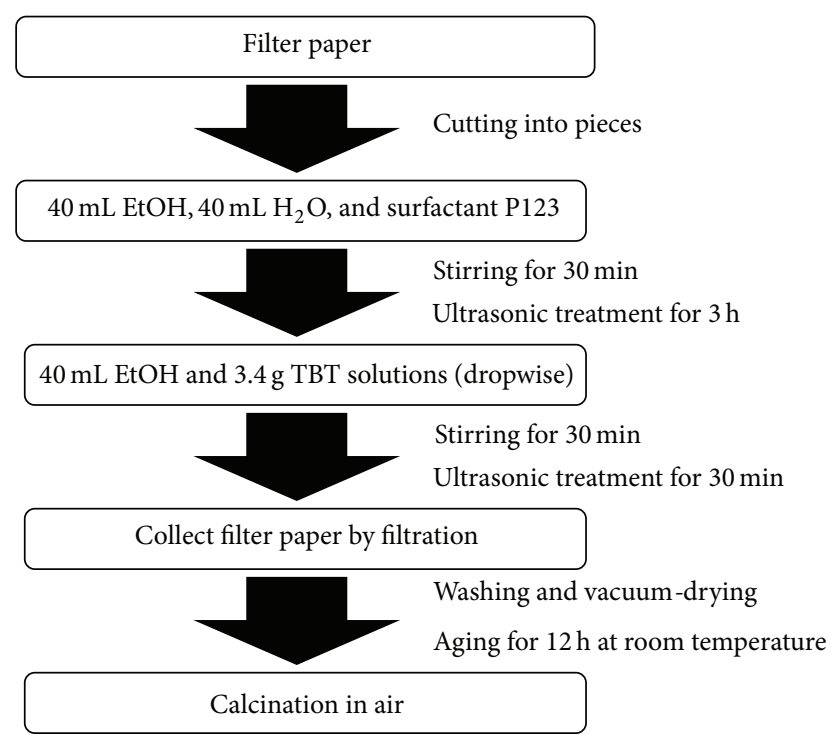

Scheme 1: Schematic illustration of the preparation process for hierarchical titania nanotubes templated by filter paper.

water (Resistivity, $18.2 \mathrm{M} \Omega \mathrm{cm}$ ). All the other chemicals were guaranteed ones and used as received.

2.2. Preparation of Porous Titania Nanotubes. The synthetic procedure of hierarchical titania nanotubes is schematically illustrated in Scheme 1. During the synthesis process, commercial ashless quantitative filter paper was used as the template of the hierarchical nanotubular structure. In a typical procedure, $0.29 \mathrm{~g}$ surfactant $\mathrm{P} 123$ was added into the mixture of $40 \mathrm{~mL}$ ethanol and $40 \mathrm{~mL}$ deionized water followed by stirring for about $30 \mathrm{~min}$. Then, $150 \mathrm{mg}$ precut squared filter paper fractions of $c a .5 \mathrm{~mm} \times 5 \mathrm{~mm}$ were immersed in and the mixture was treated with ultrasonication for $3 \mathrm{~h}$ to promote formation of the surfactant micelles. After that, $20 \mathrm{~mL} 1 \mathrm{M} \mathrm{HCl}$ aqueous solution was injected in the mixture under stirring. $40 \mathrm{~mL}$ ethanol and $3.4 \mathrm{~g}$ TBT solutions were subsequently added dropwise to the mixture under vigorous stirring at room temperature. After stirring for $30 \mathrm{~min}$, the mixture was treated with ultrasonication for $30 \mathrm{~min}$ and then the filter paper fractions were filtered off, washed with deionized water, and finally vacuum-dried at room temperature overnight. The as-prepare filter paper was firstly calcined in a tubular furnace at $120^{\circ} \mathrm{C}$ for $1 \mathrm{~h}$, then heated up to $300^{\circ} \mathrm{C}$, and kept for $1 \mathrm{~h}$ followed by $450^{\circ} \mathrm{C}$ for $4 \mathrm{~h}$. The whole process was in air atmosphere with a ramping rate of $3^{\circ} \mathrm{C} / \mathrm{min}$.

2.3. Characterizations. The micromorphologies of obtained hierarchical titania nanotubes sample were examined by S4800 field emission scanning electron microscope (FE-SEM) from Hitachi, transmission electron microscopy (TEM), and high resolution transmission electron microscopy (HRTEM, FEI Tecnai G20/JEM 2010, operated at $200 \mathrm{kV}$ ). To prepare the specimens for electron microscope observation, a small piece of the nanotubular titania sheet specimen was suspended in ethanol by supersonic dispersion. Then some of the suspension was dropped onto silicon wafer and sputtered with gold or platinum for SEM observation. And some are dropped onto copper mesh for TEM observation. The crystal phase of the obtained hierarchical titania nanotubes materials was determined by powder X-ray diffraction (XRD) recorded on a Dandong TD3500 Advanced diffractometer $(\mathrm{Cu}-\mathrm{K} \alpha, \lambda=$ $0.15418 \mathrm{~nm}$ ). Nitrogen adsorption and desorption isotherms were acquired at $77 \mathrm{~K}$ on a TriStar II 3020 surface area and pore analyzer. The linear part of the Brunauer-EmmettTeller (BET) equation was used for the specific surface area determination. And the pore-size distributions were obtained from the adsorption branch of the nitrogen physisorption isotherms using the BJH method. The Fourier Transform Infrared Spectroscopy (FT-IR) of the sample was recorded on a Nicolet Magna-IR 750 spectrometer at a resolution of $0.125 \mathrm{~cm}^{-1}$. Ultraviolet-visible diffuse reflectance absorption spectra (UV-Vis DRS) were employed to characterized the hierarchical $\mathrm{TiO}_{2}$ sample on a U-4100 spectrometer (Hitachi Japan) with $\mathrm{BaSO}_{4}$ powder as the reference standard. The surface composition of the product was determined by X-ray photoelectron spectrometer (XPS, ESCALAB 250XI, USA).

2.4. Photodegradation Experiment. A widely used dye methyl orange $\left(\mathrm{C}_{14} \mathrm{H}_{14} \mathrm{~N}_{3} \mathrm{NaO}_{3} \mathrm{~S}\right)$, which can act as a representative dye pollutant, was chosen to evaluate the photocatalytic performance of $\mathrm{TiO}_{2}$ nanotubes under UV light. Firstly, $100 \mathrm{~mL}$ aqueous solution of $\mathrm{TiO}_{2}$ catalyst $(0.2 \mathrm{~g})$ was treated with ultrasonication for $30 \mathrm{~min}$ to promote dispersion uniformity and $400 \mathrm{~mL}$ dye aqueous solution of $\mathrm{MO}(30 \mathrm{mg} / \mathrm{L})$ was prepared for subsequent photocatalytic activity test. Then, the two prepared solutions above were mixed in a quartz tube. Before irradiation, the above mixed solution was stirred for $30 \mathrm{~min}$ in the dark for establishing the adsorption-desorption equilibrium. Then under ambient conditions and stirring, the mixture was exposed to the UV irradiation produced by a $500 \mathrm{~W} \mathrm{Hg}$ arc lamp equipped with a band-pass light filter (365 $\pm 15 \mathrm{~nm}$ ). At every 2 -minute interval, about $3 \mathrm{~mL}$ suspension was withdrawn from the mixture for analysis on a Varian Cary-50 UV-Vis spectrophotometer. The initial concentration of dye solution before photodegradation experiment is noted as $C_{0}$ and the concentration of dye solution at each irradiated time interval is noted as $C$. Therefore, the percentage of residual dye can be recorded as $C / C_{0}$.

\section{Results and Discussion}

3.1. Characterization of Porous Titania Nanotubes. The XRD pattern in Figure 1(a) shows that the commercial P25 is a mixture of anatase phase and rutile phase, while the XRD pattern of our obtained porous titania nanotubes demonstrates that anatase is actually the only crystal phase (Figure 1(b)). The distinctive X-ray diffraction peaks around $25.6^{\circ}, 38.1^{\circ}$, $48.2^{\circ}, 54.1^{\circ}, 55.3^{\circ}, 62.9^{\circ}, 68.9^{\circ}, 70.7^{\circ}$, and $75.3^{\circ}$ in Figure 1(b) correspond to the (101), (004), (200), (105), (211), (204), (116), (220), and (215) crystalline planes of anatase (Figure 1(c), I41/amd, JCPDF card number 73-1764), respectively, which indicates the high crystallinity of our product. The crystallite 


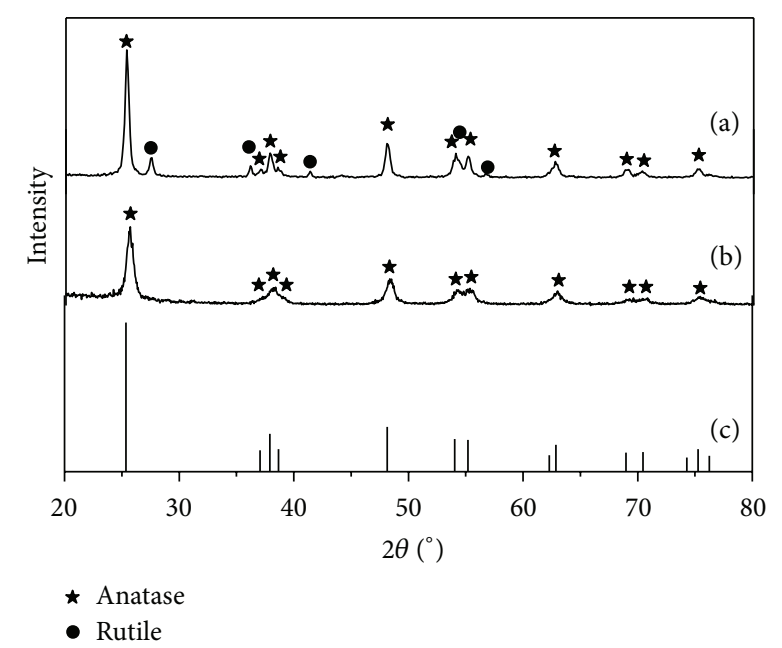

FIGURE 1: Characteristic XRD pattern of (a) P25; (b) the prepared hierarchical $\mathrm{TiO}_{2}$ nanotubes sample; and (c) JCPDF card number 73-1764 of anatase $\mathrm{TiO}_{2}$.

size can be estimated from the widening XRD peak via the Scherrer equation described as follows:

$$
d=\frac{k \lambda}{\beta \cos (\theta)},
$$

where $d$ is the crystallite size; $k$ is a constant (0.89); $\lambda$ is the $\mathrm{X}$-ray wavelength $(1.5418 \AA$ for $\mathrm{Cu} K \alpha) ; \beta$ (radian) is the fullwidth at half-maximum for the (101) peak at $2 \theta=25.6^{\circ}$; and $\theta$ is the angle of the diffraction peak (degree). The estimated average crystallite size based on the (101) peak is ca. $22.6 \mathrm{~nm}$.

The morphology of obtained $\mathrm{TiO}_{2}$ sample was observed by SEM and TEM. Figure 2(a) is the overview FE-SEM image of the sample, which shows that the titania sample really inherits the complex network structure and the hierarchical morphology of the original filter paper template, and the resulting titania is composed of many randomly intersecting titania microfibers with high aspect ratios. From the further magnified SEM image in Figure 2(b), we can observe that the tube wall of the individual titania microtube is composed of lots of fine nanotubes, which measured the tubular structure with inner diameters of $80-90 \mathrm{~nm}$ and tube wall thickness of $30-40 \mathrm{~nm}$. Figure 2(c) is a typical TEM image of an individual titania nanotube, whose hollow interior can be clearly identified. The inset in Figure 2(c) indicates that abundant intergranular pores with size of $c a .12 \mathrm{~nm}$ located in the tube-wall, which came from the aggregation of small $\mathrm{TiO}_{2}$ nanoparticles. From the HR-TEM image shown in Figure 2(d), it can be observed that the average grain size of porous $\mathrm{TiO}_{2}$ nanotubes is $\sim 20 \mathrm{~nm}$, which consists with the result of XRD analysis. Besides, the HR-TEM image in Figure 2(d) also shows that the measured lattice spacing of sample is $0.35 \mathrm{~nm}$, corresponding to the lattice distance of anatase (101) planes, which further confirms the anatase crystalline phase of the nanotubular titania product. Several multicrystal diffraction rings ascribed to the anatase phase can be observed clearly in the SAED pattern of sample (Figure 2(d) insert), which are particularly indexed (from small to large rings) as $101(d=0.35 \mathrm{~nm}), 004(d=0.237 \mathrm{~nm})$, $200(d=0.189 \mathrm{~nm})$, and $211(d=0.166 \mathrm{~nm})$. These results agree well with the XRD analysis described above.

According to the IUPAC classification of porous materials, the nitrogen adsorption and desorption curve of the obtained hierarchical porous $\mathrm{TiO}_{2}$ nanotubes material in Figure 3(a) show a type II isotherm pattern with a hysteresis loop of type H3 in the IUPAC classification [23], revealing the presence of abundant intergranular pores in the tube wall. The capillary condensation step at relative pressure about 0.3 $\left(P / P_{0}\right)$ might be attributed to the uniform mesopores in the tube walls. And the sharp step of capillary condensation at the relative pressure range of $0.5-0.95\left(P / P_{0}\right)$ is caused by the existence of macropores in the samples. From the desorption branch of isotherm as shown in the inset of Figure 3(a), the pore distribution plot of the synthesized materials was determined by the BJH (Barrett-Joyner-Halenda) method. The result indicates that the synthesized titania has mesopores with an average pore diameter of $\sim 12 \mathrm{~nm}$, which is higher than the commercial P25 (Degussa) materials (ca. $6.9 \mathrm{~nm}$ ). The BET specific surface area of the obtained titania sample was estimated about $27 \mathrm{~m}^{2} / \mathrm{g}$ and the total pore volume was about $0.11 \mathrm{~cm}^{3} / g$. Figure $3(\mathrm{~b})$ is characteristic FT-IR absorbance data of our porous $\mathrm{TiO}_{2}$ nanotubes sample. In this figure, two broad absorption bands centered around 3375 and $2995 \mathrm{~cm}^{-1}$ are observed obviously. The former is associated with the hydroxyl groups of Ti-OH at weak surface active sites and the latter is attributed to water complexes that are strongly bound to the $\mathrm{TiO}_{2}$ surface. Besides, a weak sharp absorption band, which resulted from the deformation vibration for $\mathrm{H}$ $\mathrm{O}-\mathrm{H}$ bonds of the physisorbed water, and a mixed weak peak caused by the formation of the linear chain of Ti-O-Ti are located at about $1640 \mathrm{~cm}^{-1}$ and $400-480 \mathrm{~cm}^{-1}$, respectively. However, the absorption bands corresponding to the isolated $\mathrm{OH}$ group vibrations around 3665 and $3715 \mathrm{~cm}^{-1}$ are both relatively weak that they are overlapped by the broad band, which indicates a high degree of hydration on the anatase $\mathrm{TiO}_{2}$ surfaces.

Band gaps $\left(E_{g}\right)$ of the hierarchical porous $\mathrm{TiO}_{2}$ nanotubes and P25 were estimated according to the equation as follows [24]:

$$
\alpha=\frac{B\left(h v-E_{g}\right)^{n}}{h v},
$$

where $\alpha$ is the absorption coefficient, $B$ is an absorption constant, $h$ is Planck's constant, $E_{g}$ is band gap, and $n$ equals $1 / 2$ for direct transition and 2 for indirect transition.

Figure 4(a) presents the UV-Vis spectra of the $\mathrm{TiO}_{2}$ nanotubes and P25. There is a similar striking feature for the $\mathrm{TiO}_{2}$ nanotubes and P25 that the broad absorption region extends to about $400 \mathrm{~nm}$. As the absorbance $(A)$ is proportional to the absorption coefficient $(\alpha), A$ can substitute for $\alpha$. Plots of $(A h v)^{2}$ versus $h v$ from the spectral data in Figure 4(a) are presented in Figure 4(b). The intercept of the tangent to the linear part of the curve gives a good approximation of the band gap energies of the samples. Extrapolating the linear part of the curves for the porous $\mathrm{TiO}_{2}$ nanotubes and $\mathrm{P} 25$ gives their direct band gaps of $3.43 \mathrm{eV}$ and $3.36 \mathrm{eV}$, respectively. 


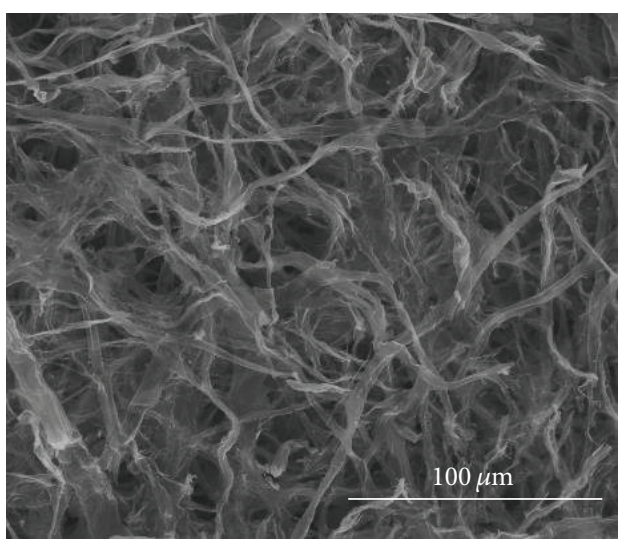

(a)

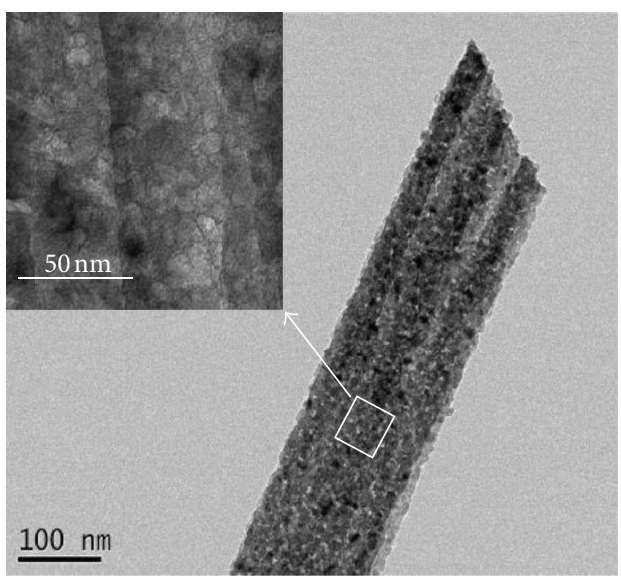

(c)

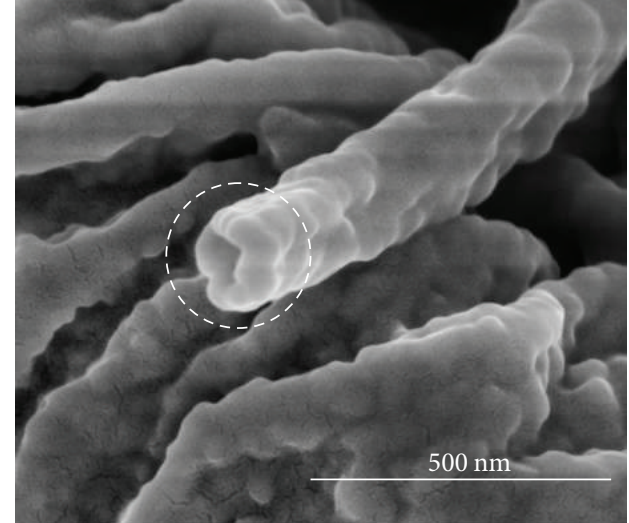

(b)

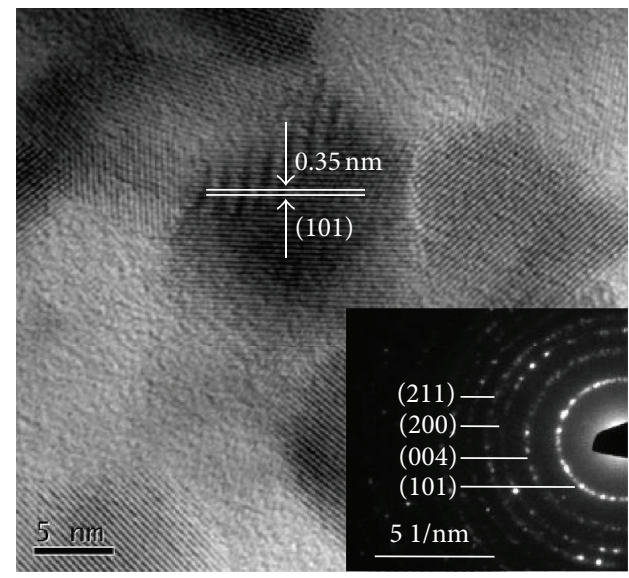

(d)

FIGURE 2: Micromorphology observations of prepared porous $\mathrm{TiO}_{2}$ nanotubes. (a) FE-SEM image. (b) Further magnified SEM image. (c) TEM image of individual titania nanotube and magnified TEM image of tube wall (insert). (d) HR-TEM image and SAED pattern (insert).

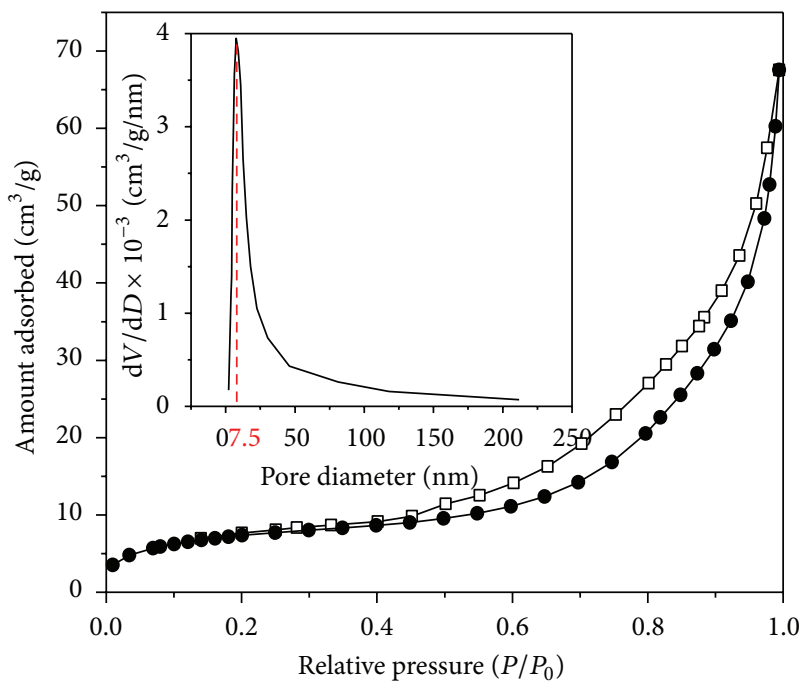

(a)

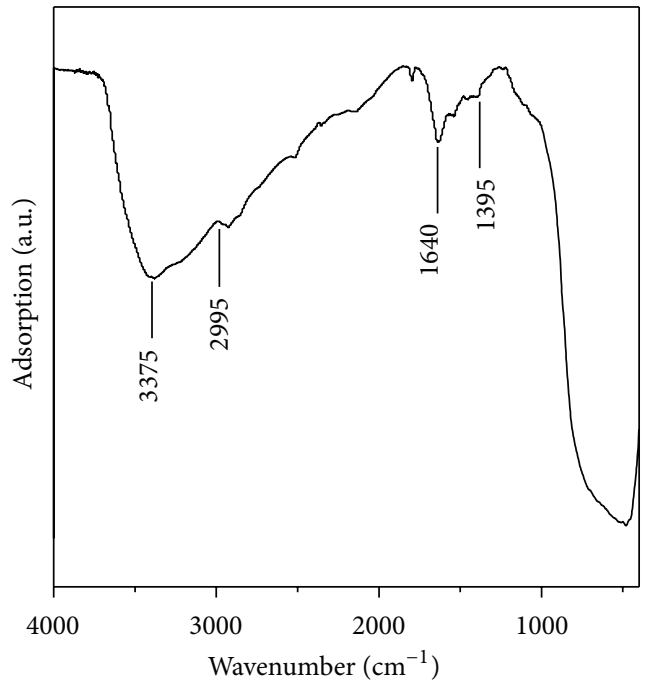

(b)

Figure 3: (a) $\mathrm{N}_{2}$ adsorption/desorption isotherms of the prepared $\mathrm{TiO}_{2}$ nanotubes and $\mathrm{BJH}$ pore-size distribution plot (insert). (b) FT-IR spectrum of the obtained porous $\mathrm{TiO}_{2}$ nanotubes. 


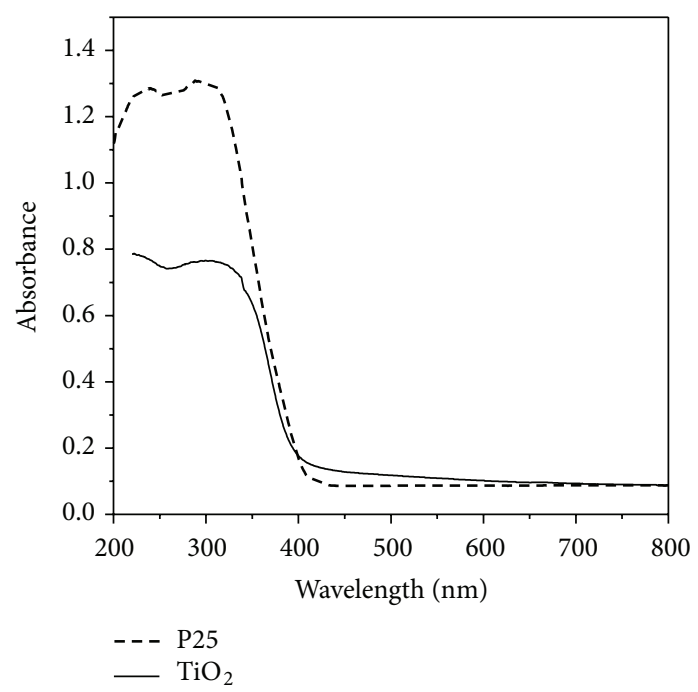

(a)

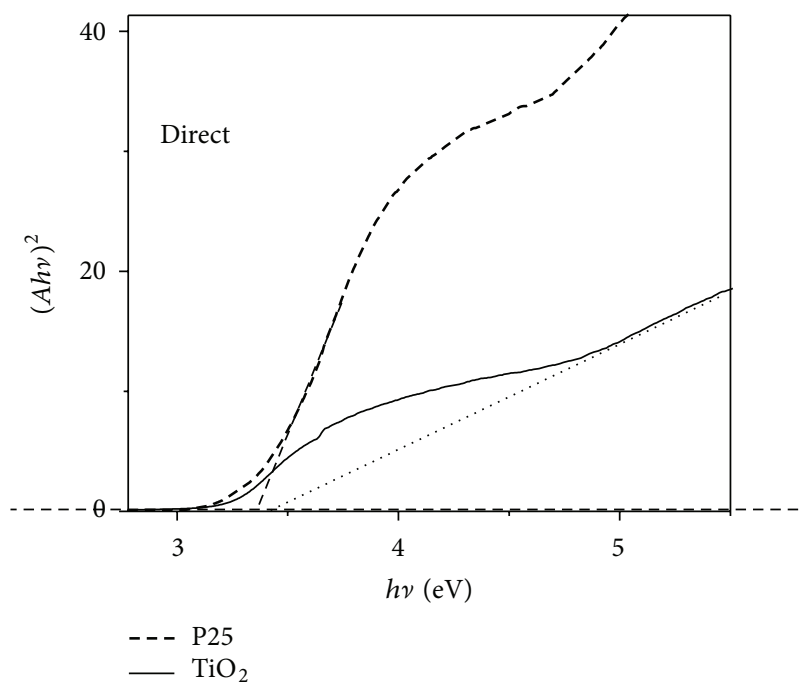

(b)

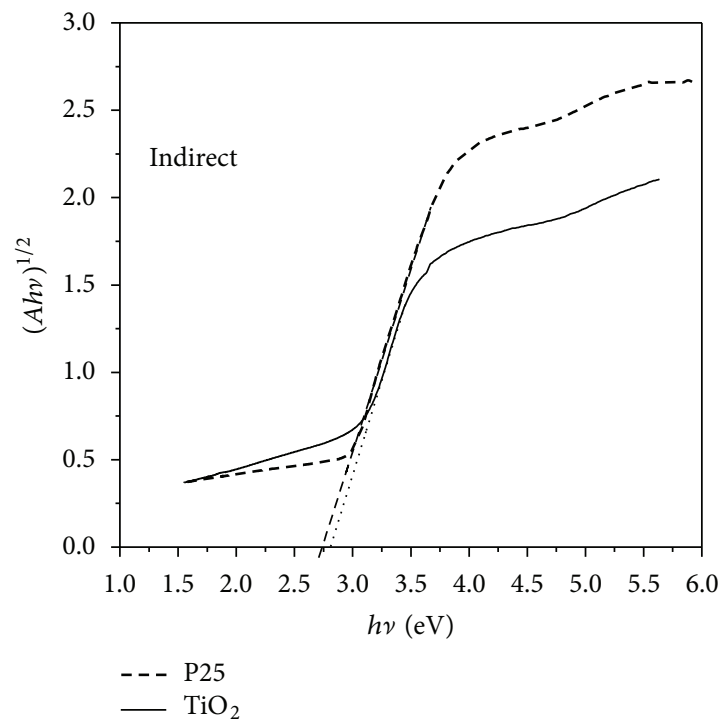

(c)

FIgURE 4: (a) UV-Vis absorption spectra of the $\mathrm{TiO}_{2}$ nanotubes and P25. (b) The plots of $(A h v)^{2}$ versus the photon energy (hv). (c) The plots of $(A h v)^{1 / 2}$ versus the photon energy $(h v)$.

These values are very close to $3.3 \mathrm{eV}$ for the experimental bulk crystal [25] and the calculated value of $3.45 \mathrm{eV}$ corresponds to $X_{1 a} \rightarrow C_{1 b}$ direct interband transition [26]. However, when the curves are plotted as $(A h \nu)^{1 / 2}$ versus $h v$, good linear relationships are obtained. Consequently, the absorption features in Figure 4(c) are those of the allowed indirect band transitions. Extrapolating the linear part of the curves for our porous $\mathrm{TiO}_{2}$ nanotubes and P25 in Figure 4(c) gives their indirect transition of $2.81 \mathrm{eV}$ and $2.73 \mathrm{eV}$, respectively. These values are very similar to the calculated value of $2.91 \mathrm{eV}$ corresponding to $X_{1 a} \rightarrow G_{1 b}$ indirect interband transition [27]. The results above indicate that the optical properties of $\mathrm{TiO}_{2}$ nanotubes are better than commercial P25 material.

Using X-ray photoelectron spectroscopy (XPS), we examined the surface chemical state and element composite of our porous $\mathrm{TiO}_{2}$ nanotubes. The XPS full spectrum shown in Figure 5(a) indicates that our $\mathrm{TiO}_{2}$ sample only contains $\mathrm{Ti}, \mathrm{O}$, and $\mathrm{C}$ elements with the chemical binding energies of Ti 2p $(459.4 \mathrm{eV}), \mathrm{O}$ 1s $(530.4 \mathrm{eV})$, and $\mathrm{C} 1 \mathrm{~s}(285.4 \mathrm{eV})$, respectively. We also measured the $\mathrm{C} 1$ s core levels to detect possible doped carbon in $\mathrm{TiO}_{2}$ lattice. Deconvolution of the $\mathrm{C}$ 1 s peak in the XPS spectrum (Figure 5(b)) shows the presence of two types of carbon bonds, that is, C-C $(284.6 \mathrm{eV})$ and Ti-O-C (288.6 eV). Doped carbon would exhibit carbon ion characteristics peaked at approximately $281.8 \mathrm{eV}$, which is different from the background peak at $284.6 \mathrm{eV}$ (carbon tape with $C_{0}$ ). As shown in Figure $5(\mathrm{~b})$, there is no carbon ion peak $(281.8 \mathrm{eV})$ for $\mathrm{TiO}_{2}$ sample. The presence of the Ti$\mathrm{O}-\mathrm{C}$ structure may be derived from the carbon in residual organic surfactant and filter paper. As shown in the $\mathrm{Ti}$ 


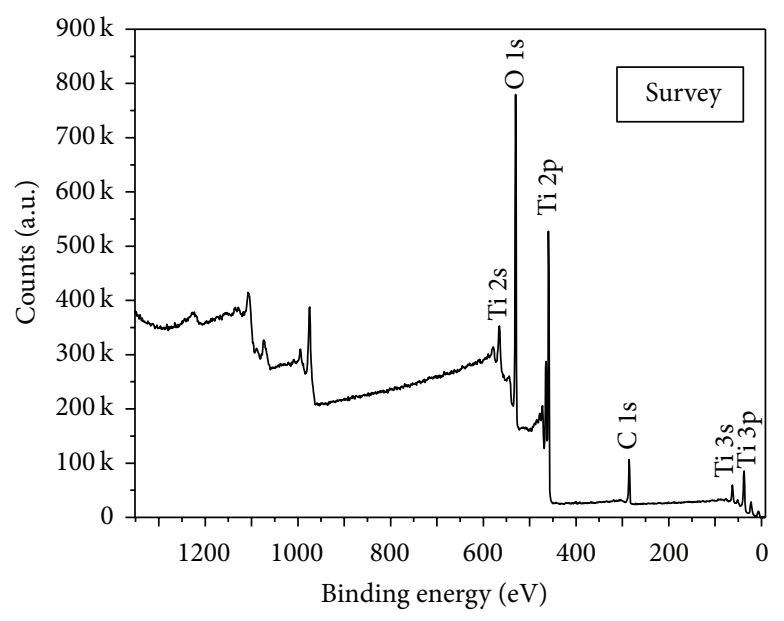

(a)

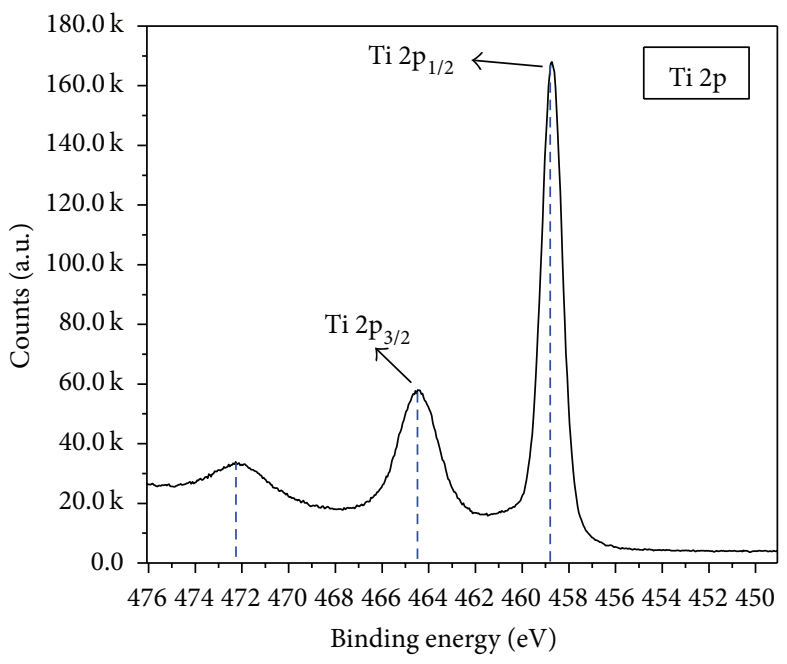

(c)

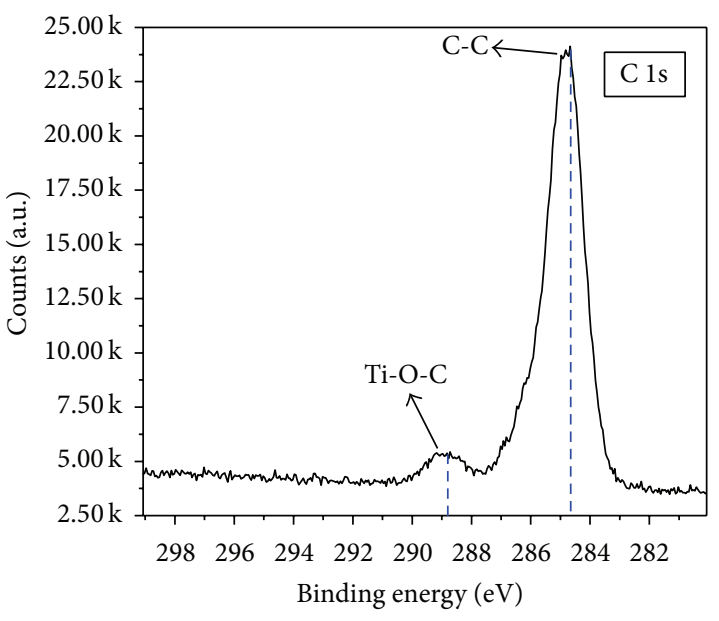

(b)

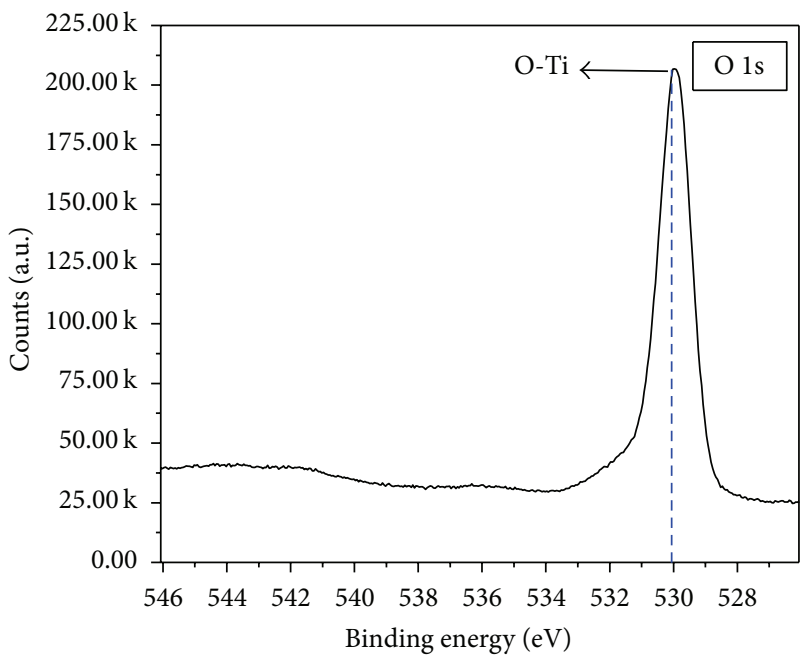

(d)

FIgURE 5: (a) XPS full spectrum of $\mathrm{TiO}_{2}$ sample. (b) High resolution XPS of C 1s and subpeak fitting chart. (c) High resolution XPS of Ti 2p and subpeak fitting chart. (d) High resolution XPS of $\mathrm{O}$ 1s and subpeak fitting chart.

$2 p$ spectral region (Figure 5(c)), there are three peaks at $458.9 \mathrm{eV}, 464.4 \mathrm{eV}$, and $472.3 \mathrm{eV}$, respectively. These peaks can be attributed to $\operatorname{Ti} 2 \mathrm{p}_{1 / 2}$, Ti $2 \mathrm{p}_{3 / 2}$, and their satellite peaks with typical characteristic $\mathrm{Ti}^{4+}$ binding energies. All Ti $2 \mathrm{p}$ signals are symmetric with no shoulders at the lower energy sides, which are significantly different from the spectra of $\mathrm{TiO}_{2}$ doped with carbon or other impurities. According to the high resolution X-ray photoelectron spectra of $\mathrm{O} 1 \mathrm{~s}$, as shown in Figure 5(d), there is a symmetric peak at $530.3 \mathrm{eV}$, indicating that the oxygen mainly exists in the form of lattice oxygen $(\mathrm{O}-\mathrm{Ti})$ in the sample.

3.2. Photocatalytic Degradation of $\mathrm{MO}$. $\mathrm{TiO}_{2}$ material is the most promising photocatalyst because of its high photosensitivity and wide band gap. Here, we evaluate the photocatalytic performance of the as-prepared porous $\mathrm{TiO}_{2}$ nanotubes by monitoring the degradation of methyl orange (MO) under UV irradiation. Before UV irradiation, the mixture of $\mathrm{MO}$ solution and the catalyst was stirred in the dark for $30 \mathrm{~min}$ to ensure that $\mathrm{MO}$ was adsorbed to saturation on the surface of catalyst. Figure 6 shows the degradation efficiency of MO over the as-prepared $\mathrm{TiO}_{2}$ photocatalyst. As shown in Figure 6(a), the color of the solutions gradually fades with the time increasing, which implies the gradual decrease of $\mathrm{MO}$ concentration in mixture. Figure 6(b) shows the absorption spectra of MO solution in the presence of the porous $\mathrm{TiO}_{2}$ nanotubes under exposure to UV light for different periods of time. The result exhibits that the characteristic absorption peak of MO at $464 \mathrm{~nm}$ rapidly decreased with the increase of exposure time and disappeared after $20 \mathrm{~min}$, which shows that $\mathrm{MO}$ is almost completely degraded under exposure to UV light for $20 \mathrm{~min}$. This demonstrates that the porous $\mathrm{TiO}_{2}$ nanotubes prepared through the present method possess excellent photocatalytic performance for degradation of MO.

Figure 7 shows the degradation efficiency of $\mathrm{MO}$ without and with the presence of catalysts. Blank experiment in the absence of catalyst but under identical UV irradiation for 20 min shows that only $2.4 \%$ of MO was degraded (black line 


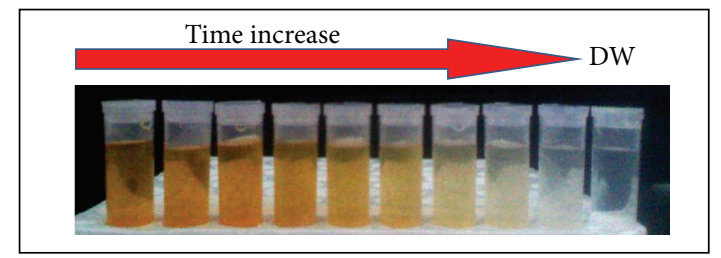

(a)

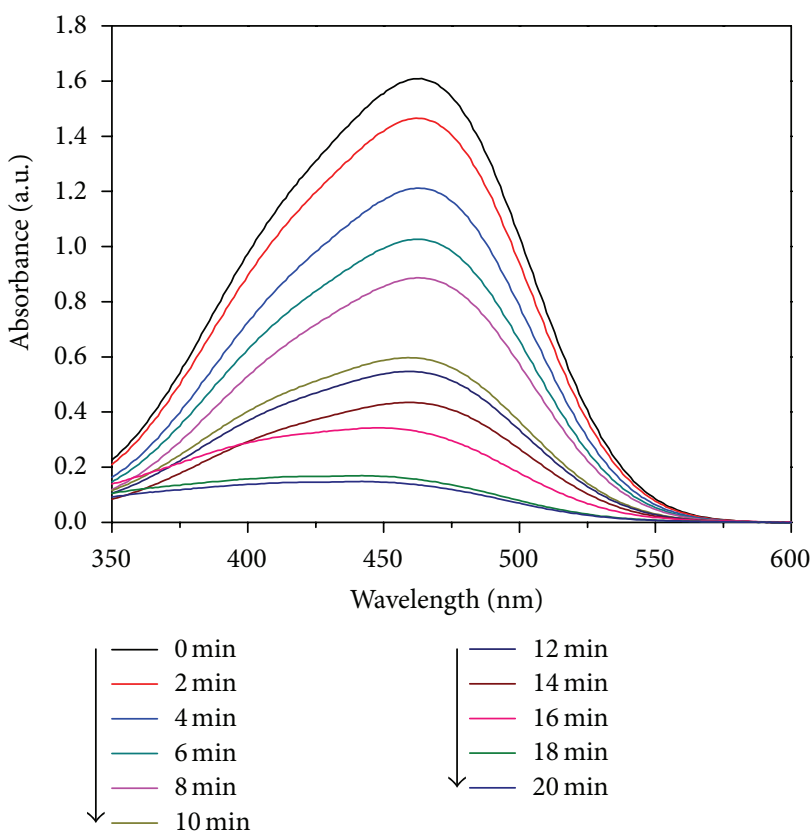

(b)

FIgure 6: (a) Photographs and (b) adsorption spectra of $\mathrm{MO}$ solutions in the presence of porous $\mathrm{TiO}_{2}$ nanotubes irradiated by UV lamp at different periods of time.

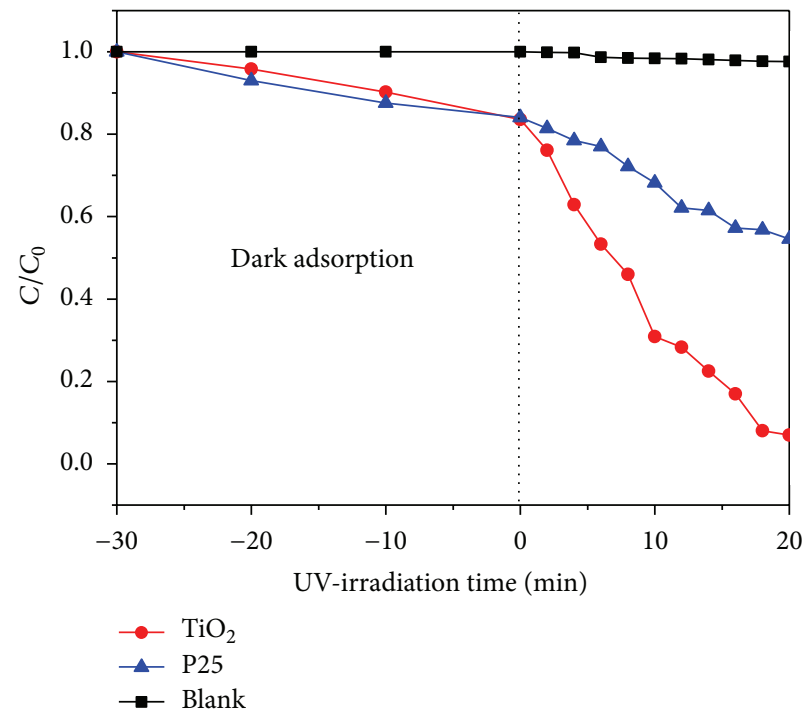

(a)

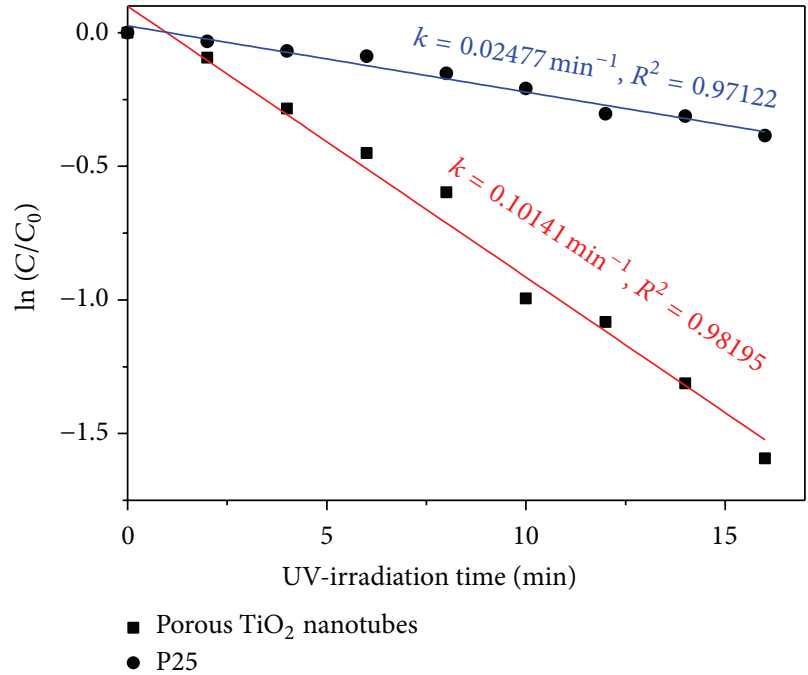

(b)

FIgURE 7: Photodegradation kinetics of methyl orange in the presence of porous $\mathrm{TiO}_{2}$ nanotubes. (a) Plot for the degradation percentage $\left(C / C_{0}\right)$ of $\mathrm{MO}$ solutions versus time intervals. (b) $\ln \left(C / C_{0}\right)$ as a function of reaction time.

in Figure 7(a)). Under the same condition, the existence of commercial Degussa P25 catalyst resulted in the increase of degradation percentage of $\mathrm{MO}$ to $45.4 \%$ under exposure to UV light for $20 \mathrm{~min}$ (blue line in Figure 7(a)). However, in the case of the porous $\mathrm{TiO}_{2}$ nanotubes, it is interesting to note that $93 \%$ of the MO in the solution is degraded after $20 \mathrm{~min}$ of UV irradiation (red line in Figure 7(a)).
Figure 7(b) shows the kinetics of photocatalytic degradation of MO under UV irradiation fitted by the first-order kinetics model:

$$
\ln \left(\frac{C}{C_{0}}\right)=-k t
$$




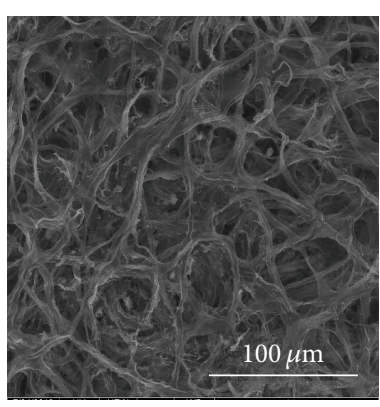

(a)

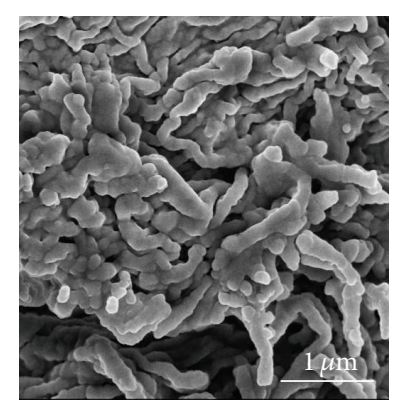

(b)

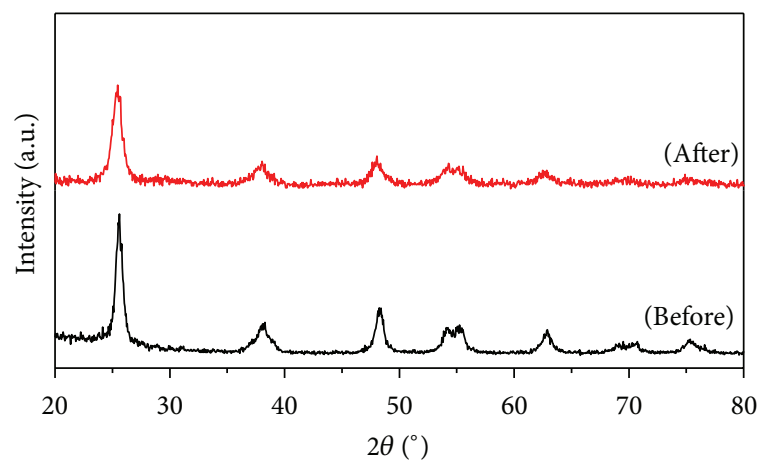

(c)

FIGURE 8: (a) Low magnified and (b) large magnified SEM images of porous $\mathrm{TiO}_{2}$ nanotubes after photocatalytic reaction for MO. (c) XRD patterns of porous $\mathrm{TiO}_{2}$ nanotubes before and after photocatalytic degradation for MO.

where $k$ is the pseudo-first-order rate constant $\left(\mathrm{min}^{-1}\right)$. As shown in Figure 7(b), the photodegradation of MO obeys pseudo-first-order kinetics. The calculated pseudo-firstorder rate of $\mathrm{MO}$ with porous $\mathrm{TiO}_{2}$ nanotubes $\left(0.10141 \mathrm{~min}^{-1}\right)$ is much larger than that of MO with P25 $\left(0.02477 \mathrm{~min}^{-1}\right)$, which means that the introduction of porous $\mathrm{TiO}_{2}$ nanotubes leads to much more significant enhancement of MO degradation rate under UV light irradiation than that of P25. It can be concluded that the porous $\mathrm{TiO}_{2}$ nanotubes exhibit more prominent photocatalytic activity than the commercial Degussa P25.

It has been reported that the photodegradation activity of $\mathrm{TiO}_{2}$ material is mainly attributed to the factors including surface area, absorptive capacity, grain size, crystalline, and morphology. Generally, high surface area and small grain size are most important for promoting the photocatalytic performance of titania materials [28-30]. However, other factors are able to influence their photocatalytic activities to a large extent as well. Though our porous $\mathrm{TiO}_{2}$ nanotubes possess a lower surface area $\left(27 \mathrm{~m}^{2} / \mathrm{g}\right)$ than commercial Degussa P25 $\left(20 \mathrm{~nm}, 48.9 \mathrm{~m}^{2} / \mathrm{g}\right)$ and a weaker adsorptive capacity in the dark adsorption of photocatalytic test (Figure $7(\mathrm{a})$ ), as well as the quite similar grain size $(\sim 20 \mathrm{~nm})$ with that of Degussa P25, the porous $\mathrm{TiO}_{2}$ nanotubes exhibit much higher photocatalytic activity than commercial Degussa P25 as depicted in Figure 7. The possible reason for the higher photocatalytic performance of porous $\mathrm{TiO}_{2}$ nanotubes can be ascribed to the following two factors. Firstly, the crystallinity of $\mathrm{TiO}_{2}$ materials is an important factor for influencing their photocatalytic performance as well [31,32]. As can be observed in Figure 1, the obtained porous $\mathrm{TiO}_{2}$ nanotubes exhibit fully pure anatase crystalline form and rather high crystallinity, which means less defects inside the sample and is in favor of the separation of photogenerated electronhole pairs and the lower recombination of photogenerated hole-electron. That means that the high crystallinity of the porous $\mathrm{TiO}_{2}$ nanotubes is beneficial to their photocatalytic performance. Besides, the abundant pores in the tube wall of the samples benefit for the penetration of light waves and lead to high mobility of photogenerated charges [31, 32]. Meanwhile, the abundant pores also facilitate the mass transport and reactants can deeply enter the catalyst through these pores, which could improve their photocatalytic activity greatly. Therefore, in spite of the lower surface area and similar grain size compared with P25, the synergistic effect arising from the high crystallinity and abundant pores on the tube wall of porous $\mathrm{TiO}_{2}$ nanotubes results in the final excellent photocatalytic performance.

Figure 8 is the characterization of porous $\mathrm{TiO}_{2}$ nanotubes after performing the MO degradation reaction. It shows that the morphology and microstructure of the $\mathrm{TiO}_{2}$ prepared through the present method were still well maintained after the reaction (Figures 8(a) and 8(b)). Meanwhile, compared with XRD pattern of the sample before photocatalytic reaction (black line in Figure 8(c)), the crystalline of porous $\mathrm{TiO}_{2}$ nanotubes was not obviously destroyed during the reaction (red line in Figure 8(c)). The result indicates that the prepared porous $\mathrm{TiO}_{2}$ nanotubes exhibit good stability during the photocatalytic degradation for MO.

\section{Conclusions}

In summary, hierarchical porous $\mathrm{TiO}_{2}$ nanotubes were successfully synthesized through a facile and efficient template synthesis strategy with the natural cellulose substance (filter paper) and triblock copolymer (Pluronic P123) micelles as dual templates. The resultant porous $\mathrm{TiO}_{2}$ nanotubes really inherited the hierarchical morphologies of the initial cellulose substances and consisted of many randomly intersecting titania microfibers with high aspect ratios. The further microstructure observation shows that the product was endowed with not only the tubular structure with tube wall thickness of 30-40 $\mathrm{nm}$ but also abundant intergranular pores with a diameter of $c a .12 \mathrm{~nm}$ on the tube wall. The result of photocatalytic degradation for MO shows that the photocatalytic activity of the porous $\mathrm{TiO}_{2}$ nanotubes is much higher than that of commercial Degussa P25. Under the UV irradiation in a short period of 20 minutes, $93 \%$ of the $\mathrm{MO}$ in the solution with porous $\mathrm{TiO}_{2}$ nanotubes was degraded while the value for the commercial Degussa P25 is only about $45.4 \%$. It can be concluded that the introduction of porous $\mathrm{TiO}_{2}$ nanotubes leads to much more significant enhancement 
of MO degradation rate than that of P25. It indicates that the porous $\mathrm{TiO}_{2}$ nanotubes prepared through the present method exhibit more prominent photocatalytic activity than the commercial Degussa P25. The simple and stable method for preparing enhanced photocatalytic activity porous $\mathrm{TiO}_{2}$ nanotubes could be extended to the fabrication of various catalysts for the degradation of organic dye pollutants.

\section{Competing Interests}

The authors declare that they have no competing financial interests.

\section{Acknowledgments}

This work was financially supported by the National Natural Science Foundation of China (21101136 and 21401015), the Key Project of Chinese Ministry of Education (212144), Natural Science Foundation Project of CQ CSTC (cstc2012jjA50037 and cstc2014jcyjA50012), the Natural Science Foundation of Yongchuan (Ycstc, 2014nc4001), and Chongqing University of Arts and Sciences (R2012CJ15, R2012CJ19, and R2013CJ04).

\section{References}

[1] S. Kohtani, S. Nishioka, E. Yoshioka, and H. Miyabe, "Dye-sensitized photo-hydrogenation of aromatic ketones on titanium dioxide under visible light irradiation," Catalysis Communications, vol. 43, pp. 61-65, 2014.

[2] L. Sun, X. Wang, M. Li, S. Zhang, and Q. Wang, "Anodic titania nanotubes grown on titanium tubular electrodes," Langmuir, vol. 30, no. 10, pp. 2835-2841, 2014.

[3] M. Bariana, M. S. Aw, E. Moore et al., "Radiofrequency-triggered release for on-demand delivery of therapeutics from titania nanotube," Nanomedicine, vol. 9, no. 8, pp. 1263-1275, 2014.

[4] J. Su, X.-X. Zou, Y.-C. Zou, G.-D. Li, P.-P. Wang, and J.-S. Chen, "Porous titania with heavily self-doped $\mathrm{Ti}^{+}$for specific sensing of CO at room temperature," Inorganic Chemistry, vol. 52, no. 10, pp. 5924-5930, 2013.

[5] M. Guo, Z. Yong, K. Xie, J. Lin, Y. Wang, and H. Huang, "Enhanced light harvesting in dye-sensitized solar cells coupled with titania nanotube photonic crystals: a theoretical study," ACS Applied Materials \& Interfaces, vol. 5, no. 24, pp. 1302213028, 2013.

[6] D. Papoulis, S. Komarneni, D. Panagiotaras et al., "Halloysite$\mathrm{TiO}_{2}$ nanocomposites: synthesis, characterization and photocatalytic activity," Applied Catalysis B: Environmental, vol. 132133, pp. 416-422, 2013.

[7] K. Nakata, T. Kagawa, M. Sakai et al., "Preparation and photocatalytic activity of robust titania monoliths for water remediation," ACS Applied Materials \& Interfaces, vol. 5, no. 3, pp. 500504, 2013.

[8] Y. Gu and J. Huang, "Precise size control over ultrafine rutile titania nanocrystallites in hierarchical nanotubular silica/titania hybrids with efficient photocatalytic activity," Chemistry, vol. 19, no. 33, pp. 10971-10981, 2013.

[9] L.-H. Chen, X.-Y. Li, Z. Deng et al., "Hydrothermal and surfactant treatment to enhance the photocatalytic activity of hierarchically meso-macroporous titanias," Catalysis Today, vol. 212, pp. 89-97, 2013.
[10] T. Luttrell, S. Halpegamage, J. Tao, A. Kramer, E. Sutter, and M. Batzill, "Why is anatase a better photocatalyst than rutile?model studies on epitaxial $\mathrm{TiO}_{2}$ films," Scientific Reports, vol. 4, article 4043, 2015.

[11] J. Yan, G. Wu, N. Guan, L. Li, Z. Li, and X. Cao, "Understanding the effect of surface/bulk defects on the photocatalytic activity of $\mathrm{TiO}_{2}$ : anatase versus rutile," Physical Chemistry Chemical Physics, vol. 15, no. 26, pp. 10978-10988, 2013.

[12] D. O. Scanlon, C. W. Dunnill, J. Buckeridge et al., "Band alignment of rutile and anatase $\mathrm{TiO}_{2}$," Nature Materials, vol. 12, no. 9, pp. 798-801, 2013.

[13] O. Ruzimuradov, S. Nurmanov, M. Hojamberdiev et al., "Fabrication of nitrogen-doped $\mathrm{TiO}_{2}$ monolith with well-defined macroporous and bicrystalline framework and its photocatalytic performance under visible light," Journal of the European Ceramic Society, vol. 34, no. 3, pp. 809-816, 2014.

[14] R. S. Hyam and D. Choi, "Effects of titanium foil thickness on $\mathrm{TiO}_{2}$ nanostructures synthesized by anodization," RSC Advances, vol. 3, no. 19, pp. 7057-7063, 2013.

[15] S. T. Nishanthi, D. Henry Raja, E. Subramanian, and D. Pathinettam Padiyan, "Remarkable role of annealing time on anatase phase titania nanotubes and its photoelectrochemical response," Electrochimica Acta, vol. 89, pp. 239-245, 2013.

[16] X. Yu, H. Wang, Y. Liu et al., "One-step ammonia hydrothermal synthesis of single crystal anatase $\mathrm{TiO}_{2}$ nanowires for highly efficient dye-sensitized solar cells," Journal of Materials Chemistry A, vol. 1, no. 6, pp. 2110-2117, 2013.

[17] R. Li, G. Chen, G. Dong, and X. Sun, "Controllable synthesis of nanostructured $\mathrm{TiO}_{2}$ by CTAB-assisted hydrothermal route," New Journal of Chemistry, vol. 38, no. 10, pp. 4684-4689, 2014.

[18] T.-D. Nguyen-Phan, E.-S. Oh, M. Chhowalla, T. Asefa, and E. W. Shin, "Hierarchical macrochanneled layered titanates with 'house-of- cards'-type titanate nanosheets and their superior photocatalytic activity," Journal of Materials Chemistry A, vol. 1, no. 26, pp. 7690-7701, 2013.

[19] N. T. Ly, T. V. Hoang, T. H. Le Ngo et al., "TiO ${ }_{2}$ nanocrystal incorporated with $\mathrm{CuO}$ and its optical properties," Advances in Natural Sciences: Nanoscience and Nanotechnology, vol. 3, no. 4, Article ID 045009, 2012.

[20] J. Miao and B. Liu, "Anatase $\mathrm{TiO}_{2}$ microspheres with reactive 001 facets for improved photocatalytic activity," RSC Advances, vol. 3, no. 4, pp. 1222-1226, 2013.

[21] E. Grabowska, M. Diak, M. Marchelek, and A. Zaleska, "Decahedral $\mathrm{TiO}_{2}$ with exposed facets: synthesis, properties, photoactivity and applications," Applied Catalysis B: Environmental, vol. 156-157, pp. 213-235, 2014.

[22] J. Li, Y. Gong, J. Xu, G. Wang, and G. Fang, "Preparation and nonlinear optical properties of Au nanoparticles doped $\mathrm{TiO}_{2}$ thin films," Journal of Sol-Gel Science and Technology, vol. 67, no. 3, pp. 527-533, 2013.

[23] M. Thommes, K. Kaneko, A. V. Neimark et al., "Physisorption of gases, with special reference to the evaluation of surface area and pore size distribution (IUPAC Technical Report)," Pure and Applied Chemistry, vol. 87, no. 9-10, pp. 1051-1069, 2015.

[24] J. Tauc, R. Grigorovici, and A. Vancu, "Optical properties and electronic structure of amorphous germanium," Physica Status Solidi (B), vol. 15, no. 2, pp. 627-637, 1966.

[25] A. Frova, P. J. Boddy, and Y. S. Chen, "Electromodulation of the optical constants of rutile in the uv," Physical Review, vol. 157, no. 3, pp. 700-708, 1967. 
[26] E. Mooser and W. B. Pearson, "The absorption edge spectrum of semiconductors," in Progress in Semiconductors, A. F. Gibson, Ed., vol. 5, pp. 53-102, John Wiley \& Sons, New York, NY, USA, 1960.

[27] X. K. Zhao and J. H. Fendler, "Size quantization in semiconductor particulate films," Journal of Physical Chemistry, vol. 95, no. 9, pp. 3716-3723, 1991.

[28] D. Li and Y. Xia, "Electrospinning of nanofibers: reinventing the wheel?" Advanced Materials, vol. 16, no. 14, pp. 1151-1170, 2004.

[29] J. C. Yu, J. Yu, W. Ho, and L. Zhang, "Preparation of highly photocatalytic active nano-sized $\mathrm{TiO}_{2}$ particles via ultrasonic irradiation," Chemical Communications, no. 19, pp. 1942-1943, 2001.

[30] T. Park, S. A. Haque, R. J. Potter, A. B. Holmes, and J. R. Durrant, "A supramolecular approach to lithium ion solvation at nanostructured dye sensitised inorganic/organic heterojunctions," Chemical Communications, vol. 9, no. 23, pp. 2878-2879, 2003.

[31] W. Zhou, F. Sun, K. Pan et al., "Well-ordered large-pore mesoporous anatase $\mathrm{TiO}_{2}$ with remarkably high thermal stability and improved crystallinity: preparation, characterization, and photocatalytic performance," Advanced Functional Materials, vol. 21, no. 10, pp. 1922-1930, 2011.

[32] C. Liu, Y. Li, P. Xu et al., "Controlled synthesis of ordered mesoporous $\mathrm{TiO}_{2}$-supported on activated carbon and porepore synergistic photocatalytic performance," Materials Chemistry and Physics, vol. 149-150, pp. 69-76, 2015. 

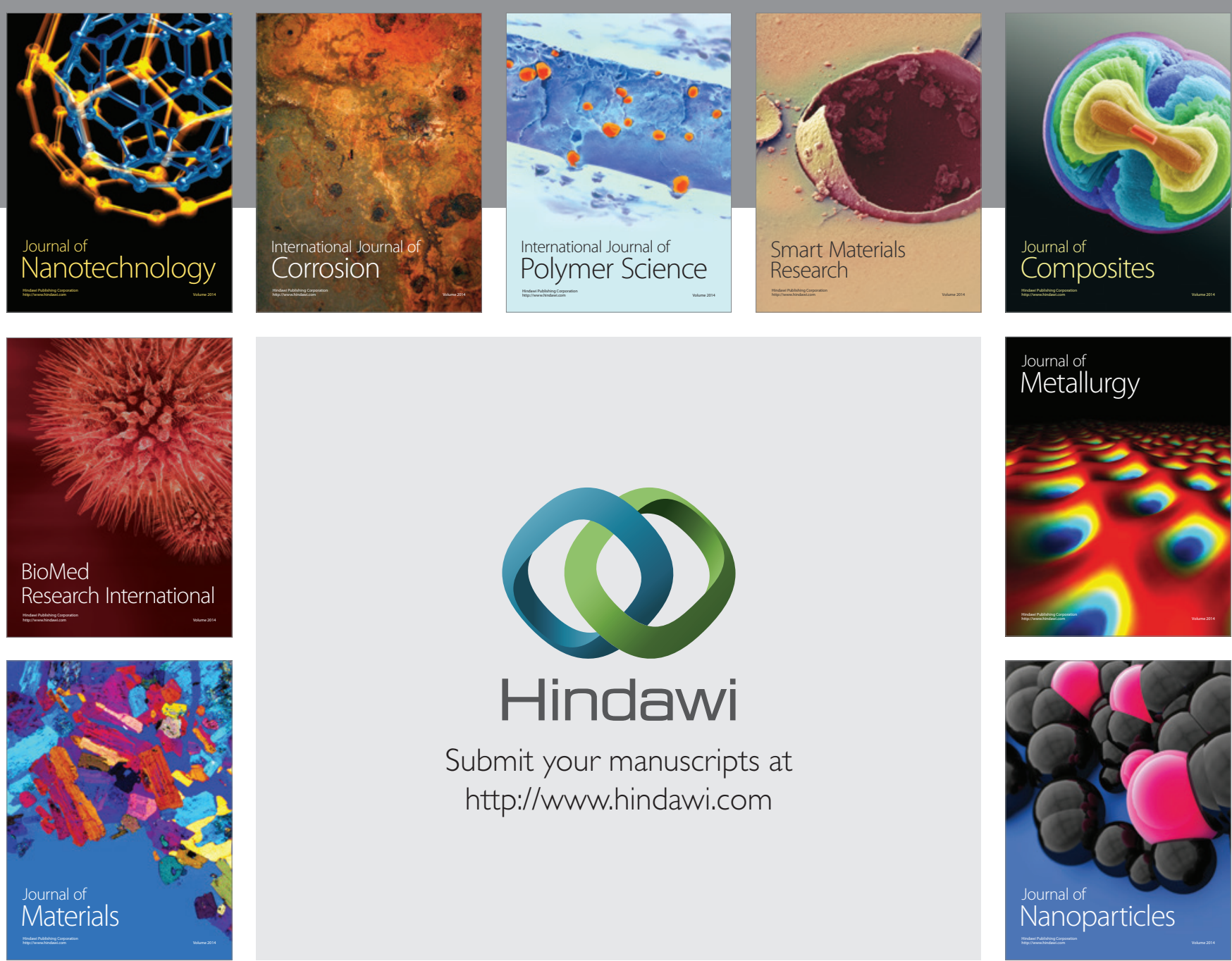

\section{Hindawi}

Submit your manuscripts at

http://www.hindawi.com

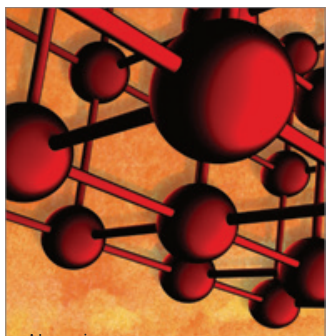

Materials Science and Engineering
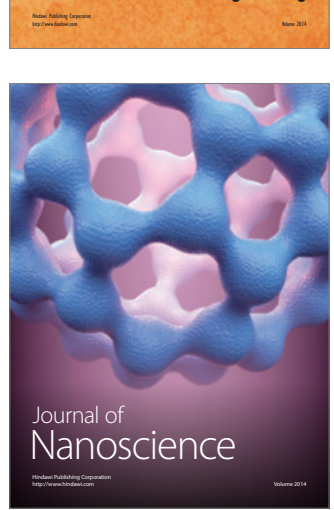
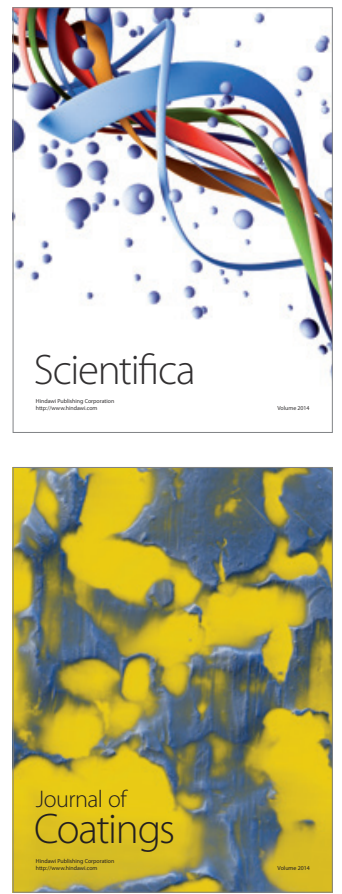
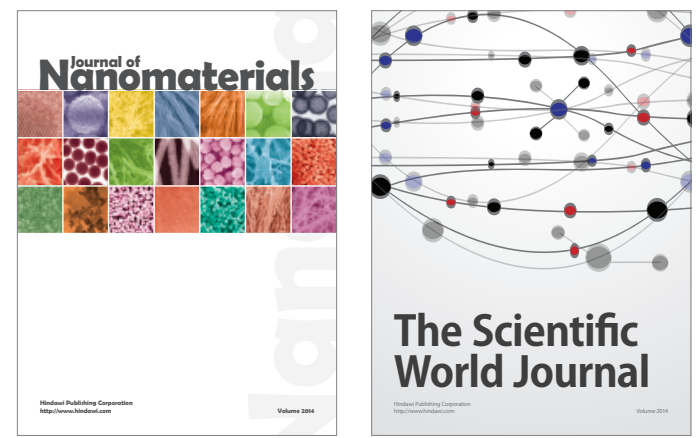

The Scientific World Journal
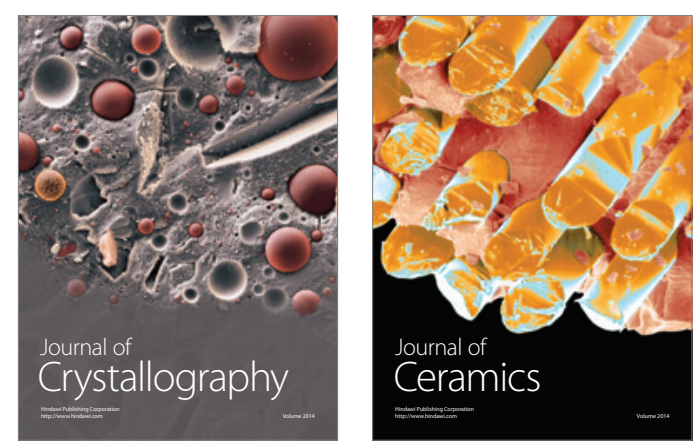
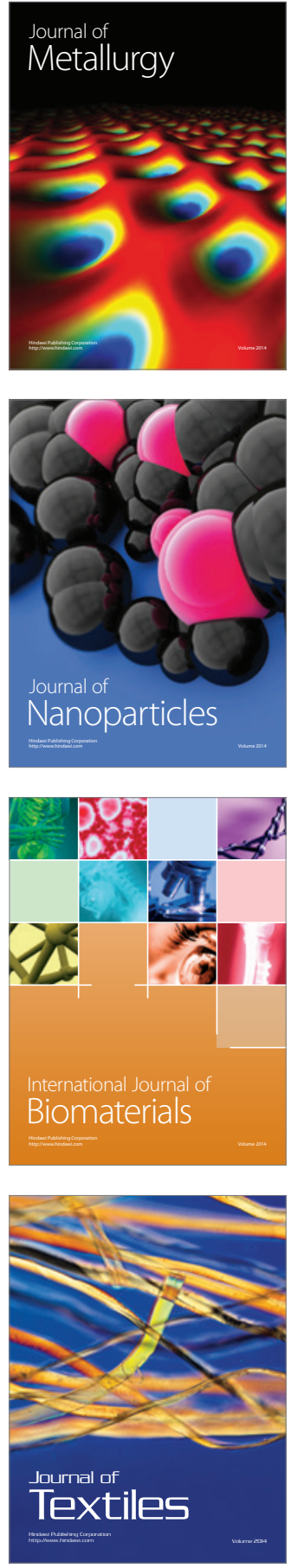